\title{
A Multirelational Account of Toleration
}

Ferretti, Maria Paola ; Lægaard, Sune

Published in:

Journal of Applied Philosophy

DOI:

10.1111/japp.12018

Publication date:

2013

Document Version

Early version, also known as pre-print

Citation for published version (APA):

Ferretti, M. P., \& Lægaard, S. (2013). A Multirelational Account of Toleration. Journal of Applied Philosophy, 30(3), 224-238. https://doi.org/10.1111/japp.12018

\section{General rights}

Copyright and moral rights for the publications made accessible in the public portal are retained by the authors and/or other copyright owners and it is a condition of accessing publications that users recognise and abide by the legal requirements associated with these rights.

- Users may download and print one copy of any publication from the public portal for the purpose of private study or research.

- You may not further distribute the material or use it for any profit-making activity or commercial gain.

- You may freely distribute the URL identifying the publication in the public portal.

Take down policy

If you believe that this document breaches copyright please contact rucforsk@kb.dk providing details, and we will remove access to the work immediately and investigate your claim. 


\title{
A Multirelational Account of Toleration
}

\author{
MARIA PAOLA FERRETTI \& SUNE LEGAARD
}

Journal of Applied Philosophy, published online as Early View article 22 May 2013, doi: 10.1111/japp.12018 Link to paper: http://onlinelibrary.wiley.com/doi/10.1111/iapp.12018/abstract

ABSTRACT Toleration classically denotes a relation between two agents that is characterised by three components: objection, power, and acceptance overriding the objection. Against recent claims that classical toleration is not applicable in liberal democracies and that toleration must therefore either be understood purely attitudinally or purely politically, we argue that the components of classical toleration are crucial elements of contemporary cases of minority accommodation. The concept of toleration is applicable to, and is an important element of descriptions of such cases, provided that one views them as wholes, rather than as sets of isolated relations. We explain this by showing how certain cases of toleration are multi-dimensional and how the descriptive concept of toleration might be understood intersectionally. We exemplify this by drawing on case studies of mosque controversies in Germany and Denmark. Finally, we propose that intersectionality is not only relevant to the descriptive concept of toleration but also captures an important aspect of normative theories of toleration. We illustrate this by discussing ideals of respect-based toleration, which we also apply to the case studies.

\section{Introduction}

This article concerns some problems that arise in the application of toleration as a descriptive concept and respect-based toleration as an evaluative standard to real-life cases. There are different understandings of toleration. According to the classical analysis, toleration requires three components: (1) an 'objection component' or 'reason for interference' consisting in some negative judgement on the part of one agent towards the 
beliefs or practices of another, a judgement which disposes the former agent to suppress, prohibit or otherwise interference with the latter; (2) a power component consisting in the first agent actually being able to interfere with the latter; and (3) an 'acceptance component' or 'reason for non-interference' consisting in some positive judgement on the part of the first agent which overrides the disposition to interfere.1Toleration actually obtains when an agent fulfilling these three conditions does not interfere with the object of objection.

But there are also understandings of toleration other than the classical one. Rather than understanding toleration as a certain pattern of action based on certain attitudes, one might understand it only to be a matter of attitudes. Toleration then denotes a character trait, which might even be a virtue, namely that a person does not hold prejudice against others.2 A third possibility is to focus solely on the pattern of action rather than on the attitudes behind it. Toleration then denotes the absence of interference, which might even be a requirement of justice, and which is ordinarily secured through a system of rights and liberties upheld by institutions such as liberal constitutional states. Both alternative uses of the term are entirely legitimate and important for specific purposes. However, in this article we suggest 1) that the classical concept better captures the complexity of certain types of cases involving minority accommodation, and 2) that it is therefore still applicable in contemporary liberal democracies.

Classical toleration is in itself a descriptive concept. Application of the concept as sketched does not say anything about whether the attitudes or relations of power are good or bad, or whether the agent in question should be tolerant or not. This is apparently denied by some theorists, e.g. Rainer Forst, who claims that toleration is a 'normatively dependent concept'.3 But the normative dependence of the concept only concerns the normative questions about what should be tolerated and whether and when toleration is good. Thus, we agree that while there is a basic non-normative concept of 
toleration, beyond that basic concept, toleration needs to invoke further normative principles or values. Our point is precisely that the concept in itself lacks any specific normative content. Toleration is often advanced as a moral or political requirement, but this is then justified on the basis of some further normative ideal, e.g. an ideal of equal respect. There are accordingly two questions at stake. One is conceptual: is toleration an applicable concept, i.e. can we sensibly and fruitfully describe specific cases in terms of toleration? The other is normative: should there be toleration in specific cases and for what reasons: is toleration good or even required and why?

The classical interpretation of toleration seems especially suited to descriptively characterise and normatively assess cases involving minority relations. Here we understand 'minority' not just quantitatively, i.e. referring to comparatively small groups, but also qualitatively, i.e. referring to groups in society viewed as different and deviant by dominant standards.4 Toleration seems an apt concept for describing minority relations, since holding minority status consists in being the object of negative attitudes and asymmetrical power, and respect-based toleration is a prominent normative proposal for how such relations ought to be handled politically.

Problems arise, however, when one attempts to apply toleration both as a descriptive concept and as an evaluative standard to real-life cases of minority accommodation. Our example concerns the controversies about mosque-building in European cities, which we take to be clear cases of minority accommodation, insofar as Muslims are a minority group throughout Europe. Mosque-building permission is often denied, partly or wholly (e.g. the Swiss ban on minarets). This is, then, clearly not an instance of toleration, but rather of intolerance of mosques. But in other cases, mosques are actually permitted. We focus on two such cases from Germany and Denmark.

The Danish case concerns the two mosque projects in Copenhagen, which were processed by the municipal council in parallel from 2009 to 2011. One project for a shia 
Islamic mosque was initiated by the religious community Ahlul Bait, which applied for building permission to the municipal council. The other project for a sunni Islamic mosque was the result of a requirement made by the municipal council that the development of a specific building site should include a representative mosque. The organisation The Muslim Council was approached by the municipal building administration and the real estate developer for this purpose. Despite these differences, the resulting public debate very much treated the two mosque projects as parts of a whole. This 'whole' was positively defined by proponents of the mosques, including a majority in the Council, as a matter of respecting freedom of religion and of furthering integration and inclusion, whereas opponents of the projects in the public debate, most prominently represented by the Danish People's Party, framed mosques in general as threats to integration, security and public order, and as symbols of undemocratic and 'un-Danish' values. After prolonged public debate increasingly dominated by opponents of the projects, the building applications were finally approved by the municipal council in 2011. The council had a clear majority in favour and processed the applications as standard planning issues, insisting that the national planning act did not permit consideration of politicised issues, such as financing from abroad or criticism of Islam, to influence the final decision.

Our argument emerged from an attempt to apply toleration theory to such cases. This attempt meets with a problem due to the fact that toleration, as usually defined, concerns specific relations. Classical toleration is a relationship between a subject objecting to and having power over an object. Real-life cases, e.g. the controversies over the building of mosques in Cologne and Copenhagen, almost always involve a multiplicity of relations, e.g. both relations between prospective mosque-builders and local councils, and relations between civil society pressure groups and Muslim communities, between different groups of Muslims, or between engaged citizens and the government. Toleration in such 
cases is not just one relation between one subject and one object; rather, there are several subjects even in relation to one single object, and the resulting relations are of different types.

Since the classical concept of toleration can only be applied to a case if one specifies the subjects and objects of toleration, application apparently has to be piecemeal, so to speak, in the sense that each relation between a specifiable subject and a specifiable object must be considered separately.5 A problem, however, arises when one considers the outcome of such an exercise: the sum of the single-relation applications of the concept or ideals of toleration simply seems not to provide a satisfactory or adequate characterisation or evaluation of the case. One might, for instance, end up with a description of a case as not involving vertical toleration at all, e.g. if public authorities are not really opposed to the mosque-project; or as not involving any social intolerance, if the mosque-critical groups have to acquiesce to the building permissions granted. The result is that the concept of toleration does not apply to these cases. Our claim is that this is both intuitively and theoretically unsatisfactory; these cases often seem to be cases of toleration, or even to involve outright intolerance.

This article offers a theoretical explanation of this mismatch and of why it does not show the classical concept to be inapplicable or irrelevant. The multiplicity of relations is not just a matter of more relations to be considered, but also makes a qualitative difference. The different relations are part of a bigger picture - together they constitute 'the case' understood as a more encompassing issue. Although an abstract construction, the concept of 'the case' is necessary to make sense of how agents behave and reason. As the example from Copenhagen illustrates, the case is the immediate object of debates, in relation to which objections are formulated and proposed solutions assessed. But the case also forms the background for an understanding of any of the particular relations between specifiable agents, e.g. the specific decision of the municipal council to grant a 
building permission to a particular party against a background of opposition from other parties. We argue that a theoretically satisfactory approach has to look at the case as a whole rather than just at the isolated relations that constitute it.

Given this theoretical perspective, it is inadequate to look at isolated relations between specific agents, as the classical concept of toleration does, since this ignores how they are part of a larger network of relationships. This is a theoretical point about the object of conceptualisation. But when we extend our focus to the case as a whole, it is clear that it not only involves all the elements of classical toleration, i.e. objection, power, and acceptance, but that any understanding of the case without attention to these factors would be inadequate. Since cases such as this involve all the factors defining classical toleration, why not describe these as cases of toleration?

Our proposal is that such cases should indeed be described as cases of toleration. So rather than dispensing with the classical concept and making do with the purely attitudinal or purely behavioural-political alternatives, we argue for the continued relevance and applicability of the classical concept to such cases. But we do this at another level of description than usual: Rather than saying of isolated relations between specific agents that they are relations of toleration in the classical sense, we say that, in the intersectionality of its multiple dimensions, the case is best understood and described as a case of toleration. So even though we retain the components of classical toleration (objection, power and acceptance), we apply the concept differently and in a way that does not understand it as picking out the internal complexities of the motivation of agents, but the multiple features of the broader social and political web of relations affecting one another and thus constituting a case of toleration.

There is a general objection to the attempt to apply classical toleration to cases in liberal constitutional states, namely that toleration is not possible in such cases, because no agents are free to interfere with citizens' practices within the space protected by 
constitutional rights. Neither public authorities nor citizens fulfil the power condition in cases involving basic rights, which therefore pre-empt toleration.6This is an argument for dropping the classical concept of toleration and instead adopting the purely attitudinal concept denoting a character trait, which can only be a supererogatory virtue, or a purely political concept denoting a regime upholding basic liberty rights (or both). One of our claims is that multi-dimensionality and intersectionality show a sense in which the classical concept of toleration is still applicable and relevant to cases of minority accommodation, since toleration in such cases is not only a matter of social attitudes or constitutional rights considered in isolation, but is crucially a matter of their interplay.

This article is structured as follows: we first explain the multi-dimensionality of toleration and lay out the concept of intersectionality. On this basis we argue that intersectionality shows how classical toleration is still applicable and relevant to the description of cases of minority accommodation in contemporary liberal democracies. After that we suggest that intersectionality might also have a normative dimension, which we discuss in relation to respect-based justifications of toleration. We then bring all these elements together in a discussion of how intersectionality makes a difference for the description and assessment of two concrete mosque controversies in Germany and Denmark in terms of toleration. Even though our argument is mainly theoretical (concerned with the concept and the justification for toleration) it has emerged from the attempt to apply toleration theory to these cases. These illustrations both exemplify and make concrete our theoretical ideas and indicate how our theoretical points are relevant to the application of toleration theory to particular cases.

\section{Dimensions of Toleration: Vertical and Horizontal}

Toleration may be applied to cases along different dimensions depending on who the subjects and objects of toleration and respect are. Relations are vertical if the subject is 
the state or some public authority and the objects are citizens or groups in society within the jurisdiction and regulative power of the authority. Relations are horizontal if both the subject and objects are citizens or societal groups.7

Vertical or political toleration is characterised by the subject of toleration having political power over the object of toleration. This is traditionally associated with the 'permission' conception of toleration, 8 in which absolutist confessional states only conceded qualified and conditional permission to religious minorities to live according to their beliefs and practices.

Horizontal toleration refers to relationships in civil society where citizens dislike or object to the practices of other citizens. In a just liberal democratic society all citizens have equal rights and freedoms and no group should be able to dominate others. Thus all groups have to put up with disliked practices of other groups as long as these do not violate any rights. There is still room, however, for horizontal toleration. This is because horizontal toleration is social not only in the sense that it concerns relations between societal groups, but also insofar as the power involved is social rather than political. Some citizens are richer and live in wealthier areas than others, who are pushed to live in ghettoes. The values and lifestyles of some groups are deeply embedded in the history of a country where others are newcomers. Factors like these illustrate how, even under a political regime of freedom and equality, there may still be unequal social power.9

\section{Descriptive Intersectionality}

Vertical and horizontal relations could in principle be completely isolated from each other. The multiplicity of relations might not make any difference. In the case of mosque-controversies, popular dislike of minarets and disapproval of Islam expressed in protest initiatives might, for instance, make no difference to the way in which public authorities relate to mosques. 
But even if vertical relations are unaffected by horizontal relations, the stance of the public authorities is likely to make a difference to the way in which the horizontal relations are played out. If authorities simply remain aloof regarding popular objections, this might weaken these reasons for objection, or it might strengthen them, e.g. if opponents of mosques make use of the public authorities' indifference to mobilise further opposition. And even if objections in horizontal relations are unaffected, relations of power surely are not: how public authorities decide to handle a given case, e.g. whether or not they permit the building of a mosque, affects how citizens and civil society pressure groups can act.

So even though relations in multi-dimensional cases could in principle be characterised in isolation, we suggest that the interpretation of multi-dimensional real-life cases has to take an alternative integrated approach. This means that the description of a case in terms of toleration a) acknowledges the multi-dimensionality of relations of toleration, and b) considers how multidimensionality affects the interpretation of the case as a whole.

The second feature of an integrated approach is concerned with what we call intersectionality, i.e. the way in which multi-dimensionality is not only a matter of there being more than one relation of toleration in a given case, but that the case cannot be adequately described in terms of toleration and/or cannot adequately be assessed normatively in terms of ideals of toleration without attention to the other dimensions.10 The idea is that relations intersect or interrelate in ways that make a difference for how the conditions for toleration can be understood, and/or for what the reasons for toleration actually justify or require, in a specific case.

Intersectionality is the reason for taking up an integrated approach in relation to multi-dimensional cases; without intersectionality, multi-dimensionality could be adequately addressed by engaging with each relation in a given case in isolation from each of the other relations in the case. But given intersectionality, an integrated approach 
is necessary to capture multi-dimensional cases adequately.

Types of intersectionality differ depending on whether they concern the description of a case as a case of toleration or the normative assessment of a case on the basis of some ideal or requirement of toleration. Descriptive intersectionality obtains when interpreting or characterising a given case in terms of toleration requires that the intersections of different dimensions of toleration are addressed.

Descriptive intersectionality concerns the application of a concept to a case. But there might be different reasons why the concept of toleration applies to a multi-dimensional case. One is that one relation affects another empirically; for instance horizontal objections causally influence the deliberations of the municipal council so that one cannot understand why the council reasons and acts as it does without reference to the horizontal objections. Intersectionality might furthermore be diachronic in the sense that opposition and acceptance need not obtain synchronically. Even if the council decides to permit the building of a mosque, which means that horizontal objections did not succeed in swaying the decision, it might have set the agenda for the decision, which will subsequently be understood against this background. Thus intersectionality will often be broader than empirical causation: if the instantiation in the case of the different components of toleration all affect the significance of the case, then there will be a reason for describing it as one of toleration even if, for example, the horizontal objections did not in fact causally affect the vertical decisions made. Intersectionality is then a conceptual matter which concerns what it means to understand a case as one of toleration.

\section{The Applicability and Relevance of Classical Toleration}

Cases of minority accommodation in contemporary constitutional liberal democracies often involve controversies over the interpretation and limits of established rights and norms as applied to minority groups. Cases about mosque-building in Europe, for 
instance, involve constitutional rights to freedom of religion and legal norms of nondiscrimination.

But this leads to an objection to viewing such cases in terms of classical toleration. The objection is that constitutional rights pre-empt toleration, since no agents in a constitutionally regulated scenario have the power to interfere with acts or practices protected by basic rights. 11

One might respond that these cases are nevertheless cases of toleration since they concern the extent of freedom enjoyed by citizens. Liberal constitutionalism provides a regime of toleration because it secures non-interference with acts or practices despite the dislike or disapproval hereof by others, and because it is justified as a way of preventing intolerance.12 But even if a case concerns the limits of the freedom granted to minorities, this does not in itself show that it is a case of toleration. The limits in question are only limits of toleration if acts taking place within these limits are acts of toleration. But the objection is precisely that this is not the case: no one has the power to interfere within these limits, so the non-interference secured by constitutional rights is not a form of toleration.

We suggest that there are two ways of understanding the noted response to the objection: one is simply to say that toleration means something different in modern liberal democracies. The classical model of toleration is inapplicable and irrelevant in relation to modern liberal democracies. This is in principle fine, but leaves unanswered the question why we should still use the same term to describe these cases; why not just dispense with the term 'toleration' altogether and focus purely on constitutional rights, e.g. on freedom of religion? Is there still any non-redundant similarity between classical and modern cases that warrants using the same term to describe and discuss them?

This leads to our alternative response: the classical analysis of toleration still applies, although in a more complicated way, which has to be spelled out. The fact that contemporary cases of minority accommodation are often concerned with the limits of constitutional 
rights protection does not in itself show that they are cases of toleration. But this does not mean that the classical analysis of toleration is inapplicable. The applicability turns, however, on the complexity of these types of cases. This is why we have introduced the notions of multi-dimensionality and intersectionality. Our claim is that, when one takes multi-dimensionality and intersectionality into account, there is still a reason to characterise these types of cases taken as wholes in terms of classical toleration. As our examples show, even though classical toleration may indeed often be inapplicable to the single relations taken in isolation, when one considers the integrated whole of these relations, they display all the features uniquely picked out by classical toleration.

In this way, we agree that the focus should be on the regime as a whole rather than on single, isolated agents of toleration. But our point is that, when one considers cases as wholes, classical toleration may still apply. Furthermore, there are good reasons to retain the classical concept, when applicable, because it captures more aspects of such cases than a redefined concept of toleration. And these aspects are precisely the ones that make the cases interesting.

\section{Normative Intersectionality}

Normative intersectionality concerns the evaluation of cases from the point of view of normative reasons for toleration, i.e. specific justifications for considering toleration as good or required. When considering descriptively complex cases, normative intersectionality obtains if justifying reasons for toleration require considering the case has a whole.

A test for intersectionality is to compare two scenarios, where a given relationship holds in both, but where it is complemented with another relationship in the second scenario. If the addition of the second relationship makes a difference to our assessment of the first, then we have a case of intersectionality. 
Whether or not certain relations can or cannot be evaluated in isolation depends on the normative ideal one endorses. Since most justifications positively evaluate relationships of toleration as furthering some other values (such as peace, equal respect, freedom of conscience), the contribution of one dimension to that value must be considered in combination with the impact of other dimensions.

Normative theories that acknowledge multidimensionality assess cases on the basis of reasons for toleration by addressing several dimensions together and the way they intersect. Ignoring that would lead to an evaluative mistake, in the same way that it would be a mistake, say, to order a drink without first considering what you are going to eat, if your goal is to maximise taste, and the taste of food depends on the drink that accompanies it. Similarly if, say, pacific cohabitation among groups is affected by the relationship between groups and the political authority, a sound normative evaluation based on modus vivendi should consider both relationships in their intersection. The existence and features (what sort of relations are relevant for the evaluation of a case) of normative intersectionality depend on the justification of toleration. In order to understand how intersectionality may work, we will focus on a conception of respectbased toleration.

Several authors 13 have proposed that this is the only conception of toleration that is not only compatible with, but also actually required by, justice. People show equal respect when they reciprocally recognise one another as morally free and equal, despite differences, e.g. in their conceptions of the good. In this way, political acceptance (in the form of recognising equal rights and liberties) can be coupled with ethical disapproval of or contempt for others' conceptions of the good.14

In our interpretation, equal respect is not simply a means of securing a narrow formal equality, but demands a wider 'qualitative equality' among different groups in society, which aims at the full inclusion of minorities as equal participants in the political 
community.15 On the basis of equal respect, minorities are not merely permitted to persist; rather, they are granted public toleration as a means to overcome the unjust aspects of their minority status.

Understood in this way, respect-based toleration not only assesses vertical and horizontal relations together, but also considers them as cases of intersectional toleration in the descriptive sense introduced earlier. While each relation taken in isolation may not be a relation of toleration, together they can not only be characterised as such, but should also be normatively assessed as such. This assessment proceeds on the basis of the requirement of equal respect, but this should not be applied to single relations taken in isolation; rather it is the interplay of these relations that determines whether a case lives up to the requirement of equal respect.

The notion of equal respect can and should of course be further spelled out and defended, and there are obviously various ways of doing this. For the purpose of the present article we do not argue for the ideal of equal respect, but merely use it as an illustration of a multi-dimensional and intersectional approach.

How respect-based toleration gives rise to normative intersectionality can be explained by highlighting what the value of toleration consists in, according to the respect conception. Toleration in a purely descriptive sense consists in non-interference.16 However, the value of toleration, according to the respect-conception, is not merely the value of non-interference. Non-interference might of course be valuable, e.g. because it leaves the receiver of toleration with negative freedom. But not all infringements of negative freedom are violations of equal respect, so the value of toleration according to the respect-conception cannot be explained by the value of negative freedom. In order to understand the value of respect-based toleration, consider first that in liberal democracies, equal respect is cashed out vertically in terms of citizen rights. But such rights are not only a matter of not actually being interfered with. The value of such 
rights also concerns one's security in not being interfered with (being free in the sense of not being vulnerable to arbitrary interference17) and having a certain legal status. In a liberal society, justice not only requires that minority groups are not interfered with in certain respects, but that their members are recognised as full and equal citizens. So toleration has to be an institutional principle rather than a discretionary act on the part of people in power.

Secondly, there is an even broader, non-institutional issue. According to equal respect positions concerned with equal social status, formal rights are not sufficient for justice; minorities also have to be recognised as full and equal citizens.18 Recognition is necessary to secure a society of equals where no group is a qualitative minority in the sense that its members are systematically regarded as less than full members of society. Toleration is therefore not just a matter of actual non-interference, but also concerns the broader institutional system of rights and the social status ideally expressed by it. From this perspective, toleration is part of the recognition of minorities as full citizens.

In cases such as the mosque controversies, the value to Muslims of being granted building permission for a representative mosque is not merely or primarily the opportunity to worship that the resulting big mosque will provide. Muslims often already have the opportunity to worship in many smaller 'cellar mosques'. The value is instead related to public visibility and recognition of Muslims as full and equal citizens that such permission might express, and thereby to the respect for Muslims as equal citizens. Multi-dimensionality is relevant in such cases because non-acceptance in one dimension may be an obstacle to achieving the further aims required for equal respect in other dimensions. Even if public authorities actually grant permission to build mosques and acknowledge that a reason to do this is that Muslims have the same rights (including freedom of religion) as others, this may not affect the minority status of Muslims if there is still sufficiently widespread opposition to mosques at the social level-even if the legal 
permission means that social groups disapproving of mosques have no direct power to prevent mosques from being built. And conversely: full social acceptance will of course not be enough, if a group is still denied equal legal rights. This is not simply the claim that we should add considerations of relative social power to those of political power, but the idea that they affect one another and should therefore be evaluated together.

So even if one could in principle consider different issues of toleration (e.g. institutional and social toleration) separately for the purpose of assessing the degree of interference and negative freedom, the normative reasons to be concerned with toleration require an integrated approach in cases where equal respect is a function of both dimensions together.

The respect conception prescribes equal respect as a function of both vertical and horizontal power relationships. Whenever a specific case exhibits descriptive intersectionality, an evaluation in terms of respect must also take into consideration how the relative power resulting from those intersectionalities affects the status of citizens.

\section{Intersectionalities of Toleration}

In order to show that classical toleration is still both applicable and relevant, but in a way requiring attention to descriptive intersectionality, recall the Danish debate about the two mosque projects in Copenhagen.19 According to the case description in Section 1, procedural constraints seem to pre-empt vertical toleration, and the actual permission seems to pre-empt horizontal toleration. Such an interpretation fails, however, to consider the case as a whole. While isolated relations in the case may not qualify as relations of toleration, the public debate about the mosque projects treated Muslims as an undifferentiated group and the so-called 'grand-mosques' as a unitary problem, despite the differences between Muslim groups and between the two mosque projects. This is a crucial aspect, which is lost if one approaches the case in a piecemeal 
fashion taking each relationship in isolation. Like so many other contemporary cases of minority accommodation, this case is therefore very much about a general minoritymajority relationship, not just about what particular constitutional rights, e.g. freedom of religion, require or prohibit in relation to particular building applications. To capture the case, one has to include both the general minority issue and the particular legal-administrative decisions.

If one considers these elements together, and thus takes the case as a whole, all components of classical toleration are present: there is dislike and disapproval, power and acceptance. These are distributed, so to speak, across the different agents involved. But when one considers the case as a whole, the different aspects nevertheless become relevant to each other. Even though the decision about whether to give building permission is formally constrained by the national planning act and background constitutional guarantees, the debate about this decision, both in the media, in the municipal council and even in parliament, was dominated by other issues all related to Muslims as a minority. So even though the actual permissions given are arguably not acts of toleration considered in a narrow legal perspective, it is artificial to abstract away from the societal context in which these decisions were taken and debated. The addition of this factor makes it reasonable to interpret the decisions as acts of toleration in the wider sense that the authorities with power to grant such permissions do so despite widely propagated popular objections to mosques.

Insofar as the case is just as much an articulation of a general minority-majority relation as one about particular building permissions, there are furthermore additional forms of power at stake. Power here means not only the legal authority to issue permissions, but also the social power to frame the mosque issue in a particular way - e.g. the power to represent Muslims as a unitary group and all mosques as raising security problems. Even though mosque opponents did not in fact have the power to prevent 
building permission from being granted, when viewing the case from the perspective of social power, it is reasonable to interpret it as also involving intolerance. Indeed, the opponents did have the power to frame the case in a way that reinforced the minority status of Muslims. This social power was exercised effectively in that opponents of mosques were successful in keeping the focus on issues that were formally irrelevant to decisions under the planning act. Opponents were able to question the permissibility of mosques and keep these issues on the public agenda even though constitutional and procedural guarantees should make such issues irrelevant.

This opposition to mosques might, taken on its own, be interpreted as a form of dislike of mosques, and thus as a form of intolerance in the purely attitudinal sense. But, again, the agenda-setting power and the framing of Muslims and mosques as problematic were not isolated from the decisions about building permission. To avoid an artificially selective view of the case, horizontal opposition and vertical permission should therefore be considered together. Then all the components of classical toleration are present.

One objection to our intersectional approach might be that it renders toleration subject-less in the sense that, from an integrated perspective focused on intersectionality, toleration is not tied to particular identifiable agents, but dispersed over a number of different agents and relations in a case. Thus, intersectional toleration does not capture the pattern of attitudes in single agents. This objection misses the point of our approach, which extends the analytical focus to the case as a whole rather than limiting it to the identification of a single (in)tolerant agent. In particular, note first that the narrow and wide perspectives are not mutually exclusive; if one takes up a wide, integrated approach focused on intersectionality, this does not preclude also examining particular agents and relations in a more narrow perspective, e.g. in terms of social power. So our proposal represents a supplementary rather than a competing interpretative perspective. What is more, our point, which we have exemplified with reference to the Danish case, is that 
there are often cases where the narrow, agent-centred perspective simply is not applicable or fails to capture the relevant features of cases, in particular the interconnectedness of agents and their different relations, which intuitively make them cases of toleration. In this respect we partly accept the criticisms levelled at classical toleration, according to which features of liberal constitutional states often pre-empt toleration. We further claim, however, that this is not a reason for abandoning classical toleration in favour of purely attitudinal or institutional conceptions, since these omit relevant and interesting features of such cases. Our proposal of a wide, integrated approach which applies classical toleration to whole cases is an attempt to show how it is still possible to capture these additional features within a single conceptual framework.

The Copenhagen mosque case thus illustrates how such an integrated approach makes classical toleration relevant. It is a case of intersectionality, because the vertical and horizontal relations in the case affect each other conceptually in that, even though they are not relations of classical toleration when taken in isolation, they together instantiate all the components required for classical toleration. Furthermore, this wider perspective on the case seems relevant because narrower and more isolated perspectives ignore what was important about the case both in the dominant public debate and framing of the case and in terms of the resulting social relations. In this sense, a multi-dimensional approach focused on intersectionality is not only possible but also necessary to adequately interpret the case.

One might accept that both vertical and horizontal relations should be considered together in this sort of case, but nevertheless deny that this calls for a general idea of multi-dimensionality and intersectionality; perhaps there is only one type of intersectionality, i.e. between vertical and horizontal relations, which is not an instance of a more general phenomenon. This would be simplifying matters again, for the interpretation of cases in terms of vertical and horizontal relations is not invariant across cases. 'Vertical' 
and 'horizontal' might denote different sorts of relations in different cases, and even a single case might involve different sorts of more or less vertical relations. A case in point is the German controversy about the building of a mosque in Cologne-Ehrenfeld. In this case, religious actors other than the Muslim communities involved also played a role. Christian churches (Evangelical and Catholic) also took part in the debate through the involvement of their representatives. In Germany these churches are recognised as 'corporations of public law' - they are neither organisations of civil society like voluntary associations, nor public authorities like municipal councils, but are invested with public functions, e.g. in education, social work and health care. Muslim communities do not enjoy this kind of status since they are not regarded as appropriately 'permanent', representative and democratic, according to Article 40 of the Basic Law.20 This makes the relationships between the Christian churches and other actors involved in the case different from both 'purely' vertical and 'purely' horizontal relations. Intersectionality therefore cannot be assumed to take the same form in all cases.

Because of their different legal status, the relationships between Christian representatives and the representatives of the DITIP, the Muslim civic association involved in building the mosque, was not a relationship among peers (and thus not horizontal). Rather, the churches played a transversal role. The intervention of the churches shows on the one hand their willingness to dialogue with other religious groups, but on the other hand - given their legal and social position - their willingness to act as intermediaries between public authorities and the Muslim associations. This role shows a clear awareness of their status as well-established groups in the country as compared with new religions. The churches' contribution to the public debate was mainly to stress and defend the value of freedom of religion in a time of progressive secularisation of society, and was thus favourable to mosque-building permission. However, some more specific interventions, such as that of BishopWolfgang Huber during the Evangelischer Kirchentag 
in Cologne (May 2007), were aimed at raising the question of the reciprocity of the treatment of Christians in countries of Muslim majority, in particular in Turkey. Drawing such a comparison between the status of Muslims in Germany and that of Christians in Turkey frames the problem of building permission as the concession of established groups that are in the position of tolerating other groups.

\section{Intersectional Respect}

We have argued that the concept of toleration may be appropriate in describing cases of majority-minority relationships if we apply an intersectional conception of toleration. We argue additionally that intersectionality is relevant from a normative point of view.

Respect-based toleration prescribes toleration when it promotes both equal rights and liberty and grants recognition to the groups that are marginalised in society. Full respect can only be achieved by considering all the dimensions that contribute to the configuration of a society of equals. For present purposes we neither endorse any specific conception of equal respect nor do we make any all things considered assessments of the mosque cases. We merely use an ideal of equal respect to illustrate that intersectionality is required not only for identifying and locating the problem where it really is but also for tracking all the aspects that are normatively relevant to the ideal of respect.

In the case of Cologne-Ehrenfeld,21 one assessment may for instance be that building permission is required by freedom of religion. Indeed, the original project of an oriental style mosque was accepted by the municipality on these terms. Yet, as the project unfolded and was publicly discussed, objections to the mosque plans were not spelled out in terms of freedom of religion. Indeed, in Germany surveys show that most people do not object to the freedom for Muslims to practice their religion (for example in 'cellar mosques'), yet they contest the visibility of mosques and the significance of their visibility in reinforcing the status of Muslims in the German society. 22 In the Cologne case a 
crucial question in the public debate concerned the proportions of the mosque, its integration in the urban landscape, and its significance in relation to the visibility of Islam and the status of Muslims in relation to the wider German society and its values. In order to understand the normative salience of granting building permission for a representative mosque, it seems restrictive to appeal to freedom of religion only, since the status of Muslim values and life style and the public visibility of Islam are the core reasons for rejection expressed on a societal level. Failure to consider these objections in interpreting the controversy misses an important normative dimension of the case, which has to do with intergroup relations. As already remarked, Muslims are constructed as a qualitative minority insofar as they are marked as newcomers and often as a threat to German standards of social behaviour, for example in the treatment of women. Equal respect of course requires some amount of non-interference of specific actors (e.g. by the opponents of mosques once permission is granted in the cases discussed), but this may not be a matter of toleration when considered in isolation, since toleration here is pre-empted by the legal framework. Yet the granting of rights (e.g. ensuring freedom of religion) and the offering of symbolic forms of recognition (e.g. not only permitting a mosque to be built, but a representative mosque) affect each other normatively and should therefore be considered together. Thus, the ideal of respect, by assigning value both to citizens' mutual regard of one another as equals, and as being entitled to equal rights and liberties, is able to grasp the interdependence between the question of building permission and the status of Muslims as a minority. The notion of respect highlights the impact of building permissions both in terms of freedom and of the recognition of Muslims.

It is precisely because the case is describable as one of intersectional toleration that the normative assessment in terms of equal respect must also address these intersectionalities, for instance by highlighting the importance of the public visibility of a representative mosque. Both the vertical and the horizontal dimensions, and how these together 
instantiate equal respect (or fail to do so), have be to be considered for the normative assessment.

Our claim that normative assessments on the basis of some ideals involve normative intersectionality is primarily a theoretical point about the structure of such assessments. But it might also make a normative difference in the sense that it provides an answer to objections to policies. Objections to representative mosques on the basis that they are not required to secure Muslims' ability to worship may for instance be countered by noting that the case is not only about freedom of religion in the sense of ability to worship, but also about equal respect in a broader sense, and that public visibility is required to secure this wider goal.

Normative intersectionality does not provide an additional argument beyond what proponents of equal respect can already say. It does not specify how exactly the various relationships should be evaluated as a whole. To clarify this is a task for normative theories of respect. However, a focus on intersectionality does make clear that equal respect cannot be assessed when considering isolated relations only. Thus normative intersectionality both shows how the descriptive multi-dimensionality of cases may also be normatively relevant given some normative ideals, and provides a formulation of how it is relevant that might be of use in practical arguments.

\section{Conclusion}

The present article has considered toleration as a descriptive concept for characterising cases and respect-based toleration as a normative ideal or requirement. Since toleration denotes social relations which involve difference, dislike or disagreement, and power, it is especially suited to characterising and assessing cases involving minority relations. We have proposed that the application of toleration theory to cases of minority accommodation needs to acknowledge the multi-dimensionality of toleration, i.e. that toleration 
cases often involve multiple social relations with different agents and different forms of power. Our central claim is that different relations should be taken together when characterising or evaluating cases in terms of toleration, since such a wide perspective alerts us to what we have called intersectionality. Intersectionality explains why an isolated or piece-meal analysis or evaluation of cases is often inadequate. We hope to have exemplified the sense of intersectionality and to have shown its relevance.

Maria Paola Ferretti, Exzellenzcluster 'Die Herausbildung normativer Ordnungen',Technische Universität Darmstadt, Institut für Politikwissenschaft, Residenzschloss, D-64283, Darmstadt, Germany.ferretti@pg.tu-darmstadt.de

Sune Laegaard, Philosophy and Science Studies Section, Department of Culture and Identity, Roskilde University, Universitetsvej 1, P.O. box 260, DK-4000 Roskilde, Denmark. laegaard@ruc.dk

\section{Acknowledgments}

Earlier versions of this paper were presented at a RESPECT project workshop at the University of Nicosia, July 2011, at the ECPR general conference at the University of Iceland, August 2011, at the conference Debating Toleration at the University of Pavia, November 2011, and at the SAP Annual Conference in Oxford, June 2012. Special thanks to Ayelet Banai, Magali Bessone, Elisabetta Galeotti, James Gledhill, John Horton, Cillian McBride, Anna Moltchanova, Valeria Ottonelli, Enzo Rossi, Simon Thompson, Nadia Urbinati, DavidWeberman and two anonymous journal referees for very helpful comments. The research for this article was carried out within the framework of the RESPECT research project (GA no: 244549) funded by the European Commission's 7th Framework Program. The information and views set out in this article are those of the authors only and do not necessarily reflect the official opinion of the 
European Union.

\section{NOTES}

1 Glen Newey, Virtue, Reason andToleration (Edinburgh: Edinburgh University Press, 1999); Rainer Forst, The

Right to Justification: Elements of a Constructivist Theory of Justice (New York: Columbia University Press, 2011).

2 John Horton, 'Toleration as a virtue' in D. Heyd (ed.) Toleration:An ElusiveVirtue (Princeton, NJ: Princeton University Press, 1996), pp. 28-43.

3 Forst op. cit., Chapter 6.

4 Anna Elisabetta Galeotti, Toleration as Recognition (Cambridge: Cambridge University Press, 2002). 5 Since toleration requires subjects with agency, the application of the concept presupposes a sociological interpretation of relations as involving agents. This raises a number of questions: 1) Can groups and institutions be agents? 2) If so, how unitary are groups and institutions; how does one determine when one should ascribe an act to the entire group or to a sub-part of the group? 3) Are some of the issues discussed not better addressed in terms of structure rather than in terms of agency?The arguments presented here are

independent of any specific stance regarding 1) and 2). The answer to 1) will depend on which theory of agency one assumes. The answer to 2) will most likely depend on the context and the purpose of one's interpretation. Regarding 3), structure and agency perspectives might in some cases merely be complementary

descriptions of the same case. In other cases, they might be mutually exclusive.

6 Newey 1999 op. cit.; David Heyd, 'Is toleration a political virtue?' in M. Williams and J. Waldron (eds) Toleration and its Limits: Nomos XLVIII (NewYork: NewYork University Press, 2008), pp. 171-94.

7 The vertical/horizontal distinction relied on in this article is not necessarily clear-cut. An actor that is reasonably interpreted as the subject of vertical toleration in one context might be interpreted as a party to a horizontal relationship in another context.A local council might, for instance, be a public authority relative to the horizontal relations between citizens, but might itself stand in horizontal relations to other local 
councils relative to which the national government is a public authority. The main point therefore is that there might be different subjects of toleration and that cases therefore might be multi-dimensional. The vertical/horizontal distinction is merely an often-useful way of capturing this multi-dimensionality.

8 Forst op. cit.

9 Bernard Williams, 'Tolerating the intolerable' in A.W. Moore (ed.) Philosophy as a Humanistic Discipline (Princeton, NJ: Princeton University Press, 1996), pp. 126-34.

10 The concept of intersectionality given here draws on the application of it to the Danish mosque-debate in

Sune Lægaard, 'Grand-Mosque' projects in Copenhagen: Intersections of respect, tolerance and intolerance in the distribution of public space', Politics in Central Europe 6 (2010): 60-80.There are some differences of terminology however, since we do not here rely on the cumbersome distinctions between intrinsic and extrinsic intersectionality and between bottom-up and top-down intersectionality. Knight touches upon themes similar to those we discuss under the label of intersectionality, but in relation to the institutionalisation

of toleration rather than to the issues of conceptual and normative application that we are concerned with (Jack Knight, 'Institutionalizing toleration' in I. Crepell, R. Hardin \& S. Macedo (eds) Toleration onTrial (Lanham, MD: Rowman and Littlefield, 2008), pp. 31-48).

11 Newey 1999 op. cit.; Heyd op. cit.

12 Peter Jones, 'Making sense of political toleration', British Journal of Political Science 37 (2007): 383-402. 13 Thomas Nagel, Equality and Partiality (Oxford: Oxford University Press, 1991); Thomas M. Scanlon, 'The difficulty of tolerance' in D. Heyd (ed.) Toleration: An Elusive Virtue (Princeton, NJ: Princeton University Press, 1996), pp. 226-39.

14 Forst op. cit.

15 Galeotti 2002 op. cit.; Forst op. cit.

16 The relevant sense of 'non-interference' has to be contextually specified, just as the question of what counts

as objection and power (see Horton op.cit.; Sune Lægaard, 'Normative interpretations of diversity: The Danish cartoons controversy and the importance of context', Ethnicities 9 (2009): 314-333). Whether 
granting building permission is non-interference is not a question about acts or omissions, since any decision

by the Council in response to an application is an act. Which acts counts as tolerant might be understood in relation to the applicant's freedom (Jones 2007 op.cit), although this will then seem intolerant to other parties (Newey 1999 op.cit.). However our aim here is not to make all things considered judgments about what decision would be appropriately tolerant in these cases, but concerns more general conceptual questions. So we do not take a stand on this issue here.

17 cf. Philip Pettit, Republicanism (Oxford: Oxford University Press, 1997).

18 Galeotti 2002 op. cit.

19 Described in more detail in Lægaard 2010 op.cit.

20 Maria Paola Ferretti \& Claire Moulin-Doos, 'Corporatism and "new groups". Emerging value conflicts in contemporary Germany', in G. Calder \& E. Ceva (eds) Diversity in Europe: Dilemmas of DifferentialTreatment

in Theory and Practice (London: Routledge, 2011), pp. 140-156.

21 For a detailed description of the case see Claire Moulin-Doos, 'The debates and actors around the construction of a representative mosque in Cologne-Ehrenfeld, Germany', Respect ProjectWorking Paper Series

10 (2011).

22 Detlef Pollack, Deutsche sind viel weniger tolerant gegenüber Muslimen/German are much less tolerant of

Muslims (Münster: Münster Universität-Excellenzcluster Religion und Politik, 2010). Online at: http://www. uni-muenster.de/Religion-und-Politik/aktuelles/2010/dez/PM_Studie_Religioese_Vielfalt_in_Europa.html (accessed 12 September 2012). 